\title{
Designing contextual, efficient, and resilient land regeneration systems for mine closure under conditions of extreme uncertainty and resource constraints
}

\author{
B Warr BetterWorld Energy Ltd, Zambia; Stellenbosch University, South Africa
}

\begin{abstract}
This paper provides personal and professional reflections on characteristics of the economic, environmental, and social system within which we all operate and which are of particular relevance to the mining industry, before describing briefly a very promising approach to mine facility regeneration that was designed on the basis of these reflections and which has been successfully piloted in Chingola, Zambia. The paper is organised loosely into four sections each dealing with a dimension of coupled economic-environmental-social systems; the last presenting a specific example of a world first pilot of the regeneration of a disused copper tailings facility in Chingola, Zambia-a project designed following reflection on the system itself. The three characteristics considered are:
\end{abstract}

1. Environmental systems are complex, not just complicated. Humans find complexity hard to manage but benefit from their resilience.

2. Economics is about more than just prices and efficiency. There are thermodynamic constraints, non-priced goods and services, trade-offs, and strong dependencies that convenient assumptions cannot override without sacrificing resilience.

3. By mimicking and managing certain characteristics of complex systems that are both efficient and resilient, we can identify and develop holistic regenerative business models for mine closure.

The first topic deals with the topic of complexity and seeks to illustrate how our tendency to silo disciplines, to seek simplifications, and apply reductionist thinking is poorly adapted to the current set of problems we face as a species-where resilience or agility is of the utmost. The second topic considers how reductionist thinking has given rise to some absurd economics and how an economic system that has arguably sacrificed resilience for efficiency can predate itself. Here, I consider the overlooked role of natural resources and technology in economic growth providing a framework, 'exergy economics' that reveals the importance of efficient natural resource extraction, processing and consumption in driving economic growth. It also reveals how the global engine of growth could falter with drastic implications for mine closure plans, as well as some aspects of the technical challenges that the industry faces in the future. In the third section, we look at the history and future of mining and mining-related activities in Chingola, Zambia, and describe how our project seeks to provide a new option in the seasonally dry tropics and the relevance of our approach more globally.

Keywords: inclusive regeneration, copper tailings, phytostabilisation, complexity, resilience, efficiency

\section{$1 \quad$ Recognising soil as complex systems}

The first people that all undergraduate soil scientists are introduced to are the two founding fathers of the discipline of soil science, Vasily Dokuchaev and Hans Jenny, a Russian and an American. Dokuchaev (1846-1903) was among the first to formally state that soil is "a natural body having its own genesis and its own history of development, a body with complex and multiform processes taking place within it" (Krasil'nikov 2015). Previously, soil had been considered to be dead-a deterministic product of physicochemical transformations of rocks. Half a century later, Hans Jenny described soils mathematically as being the result of a suite of factors operating over time (Jenny 1941):

$$
\text { soil }=f(\text { climate }, \text { biota }, \text { relief }, \text { parentmaterial, time } \ldots)
$$


The brackets are left open to indicate that this is a non-exhaustive list of potential factors that determine how soils form and evolve as a function of state variables that determine ecosystem properties. For the soil scientist, then commences the life-long process of evaluating relative importance (lacking prices), linking, and juggling physical, chemical, and biological process dynamics and conferring with specialists across the domains. Both Jenny and Dokuchaev were pedologists; the branch of soil science focused on the study of soil in its natural environment. At this point, it is perhaps valid to ask 'why would anyone study soils in a way that is divorced from their natural environment?'. We will return to this point later in the paper.

Since these early days, it is our understanding that soils display characteristics of open thermodynamic systems such as multiscale interactions and coupling, positive and negative feedbacks, non-linear dynamics, emergence, and a sensitive dependence on initial conditions (Table 1). But despite our early understanding of soils as complex systems, it can be argued that soil science is a discipline bifurcated repeatedly and purposefully, applying reductionist methodologies as a means of coping with complexity, as the 21 Divisions of the International Union of Soil Scientists indicates. Belatedly, the First Complex Soil Systems Conference was held in 2014, hosted by the Earth Sciences Division of Lawrence Berkeley National Laboratory (Faybishenko et al. 2016).

Table 1 Characteristics of complex systems (adapted from University of Gröningen n.d.)

\section{Emergence}

Sudden transitions/tippingpoints/non-linearity

\author{
Limited \\ predictability/fundamental \\ uncertainty
}

Large events

Evolutionary dynamics

Self-organisation
Emergent behaviour results from interactions between the individual elements in the systems behaviour at the level of the system as a whole.

Complex systems show non-linear dynamics and may suddenly change behaviour or move to another regime. They may move from a high degree of stability to very unstable behaviour.

The behaviour of complex systems cannot be predicted well. Small changes in initial conditions or history and non-linear behaviour can lead to very different dynamics over time.

Relatively small changes may lead to large effects. This is the case if a complex system is close to a tipping point. It is therefore related to the non-linearity of complex systems, often referred to as Black Swans or catastrophic failures.

Complex adaptive systems are often shaped by evolutionary dynamics and cycles of variation-selection-multiplication-variation starts. The system is never at rest. There is no movement to a knowable end point or equilibrium. There is constant change and innovation.

Complex adaptive systems operate without central control. However, they are often characterised by a certain order. They are often described as 'bottom-up self-organising'.

In the conference proceedings, it is stated that:

\begin{abstract}
"Conventional deterministic soil and hydrologic experimental methods and models are not adequate for developing a predictive understanding of complex soil systems, now or under near future conditions, but also indicates availability of alternative approaches to understanding such systems. New approaches are needed."
\end{abstract}

It is encouraging that after almost 120 years, the first and perhaps most important scientific observation of soil and its complexity-that defines the challenge we face as soil scientists-is being addressed head on. 
Except for environmental science and ecology, evidence suggests that complex systems research is fragmented and undertaken by isolated research groups (Fraccascia et al. 2018). The very high level of connectivity within soil ecosystems - where biologically mediated flows of energy, materials and information have developed into regulatory feedback loops-characterises highly resilient soil ecosystems. The downside of connectivity is -if negative damping feedback thresholds are perturbed-that impacts can spread and be reinforced very rapidly across the system. Economies and businesses also benefit and suffer from connectivity, but through extreme reductionism and siloing, the complexity and connectivity of the system of production and consumption to the stock of natural capital and flows of ecosystem services has been poorly incorporated into mainstream thinking and, as a result, remained extremely poorly managed. Industrial agriculture provides a very clear example of where a drive for incremental efficiency-defined using highly reductionist or incorrect metrics and at the expense of the resilience of the soil-plant/s/animals-water system-is causing irreversible global change.

\section{Absurdity and efficiency in economics}

If asked, it would be reasonable to expect that most people assume that the process of mining will generate profits; a required fraction of which will be allocated for suitable mine closure. But this depends largely on our ability to forecast the state of the future economy-something that economics is not very good at. Economic growth theories and models have an appalling track record of forecasting certain characteristics of the complex evolving economic system, such as growth itself (or collapse). The standard growth equation in economics for the past 50 years is of the form:

$$
Y=A_{t}\left(K^{\alpha} L^{\beta} E^{\gamma}\right)
$$

where:

$$
\begin{array}{ll}
Y & =\text { GDP. } \\
K & = \\
L \quad= & \text { labour. } \\
E \quad= & \text { energy. } \\
\alpha, \beta, \gamma= & \text { exponents }{ }^{1} \text { that sum to one (constant returns-to-scale), and are assumed equal to the } \\
& \text { cost shares of the factors of production in the national accounts. }
\end{array}
$$

The multiplying term, $A_{t}$, is a time-dependent multiplier. There are two things to notice about this equation. Firstly, $A_{t}$ is a means of dealing with our ignorance, in a way similar to that expressed by Jenny when leaving his parentheses open. But the approach is quite different. The standard approach to growth forecasting in economics is to fit the function (Equation 2), then fit the residual using an exponential fit providing approximately $3 \%$ growth per annum. This is based largely on the assumption that growth in the future will follow a similar trajectory to that seen in the past. Other common assumptions of the neo-classical paradigm encapsulated in Equation 2 include:

1. Abstract flows of money are both input and output, implying that economies operate as perpetual motion machines, nature is not needed, and there are no negative externalities (Ayres \& Kneese 1969).

2. Productivity of a factor is proportional to how much it costs in the national accounts. Raw materials (food, fodder, ores, energy) are not important in driving growth. This assumption only holds for a single sector economy (Ayres et al. 2013).

\footnotetext{
${ }^{1}$ These exponents are often referred to as the marginal elasticities of production in a Cobb-Douglas production function.
} 
3. The factors of production are unrealistically substitutable, such that we can remove energy (natural resources) from the equation, to be substituted with capital and/or labour and production can continue.

4. Technology is undefined and technological progress as a driver of growth is simply assumed and only ever explained a posteriori. The future will be like the past.

The Nobel Prize was awarded to the economist who identified the unexplained residual from the fit using only capital and labour, and called it technology and modelled it as a continuous function of time. The dominant neo-classical approach has the following implications that are relevant to anyone thinking about forecasting future economic growth rates:

1. Growth is assumed not modelled (3\% per annum), alternatively stated 'we will all be better off in the future regardless'.

2. Most growth is attributed to labour productivity, while natural resource supply and primary commodities (energy, ores, and food) are relatively cheap and therefore, considered less productive.

3. Our technology options are as unconstrained as they are undefined. But how realistic are these assumptions?

Challenging and offering alternatives to these widely accepted assumptions has been the focus of the heterodox economists or ecological economists such as Georgescu-Roegen, Daly, and Ayres (Georgescu-Roegen 1971; Daly 1989; Ayres 1998). In our 2009 book The Economic Growth Engine: How Energy and Useful Work Create Material Prosperity, we offered an alternative approach-one that imposes thermodynamic constraints on the models of the economic system and provides for a more realistic representation of how technology works to reduce costs and create opportunities for growth in the economy (Ayres \& Warr 2009). The economy, like the soil, is an open thermodynamic system with multiscale interactions and coupling, positive and negative feedbacks, non-linear dynamics and emergence that define its industrial metabolism. Our work focused on understanding how natural resources are used and how dramatic improvements in the efficiency of energy and materials conversion and use processes contribute to growth.

Every material substance can be regarded as congealed energy because mass and energy are essentially equivalent. But mass says nothing about the ability to do work, which is a reflection of differentiation from the background environment. Some kinds of energy are more useful than others. For example, the ocean contains a lot of heat but the heat energy in the ocean is not very useful for doing useful work. Physicists call the useless part anergy and the useful part exergy. Exergy is that component of energy capable of doing work.

Some work is useful to humans, i.e. to drill holes in the ground and reduce ores to their elements, and so on. Other kinds of work, including creating eroding gullies in soils, or dispersing pollutants, or breaking down pollutants into less harmful substances, or photosynthesis, are more or less useful. The ability to do work, and being different from the background environment, gives values to materials like ores. All kinds of workboth those essential to all economic activities and those peripheral to the industrial economy-are subject to the laws of thermodynamics. The link between exergy and economics is usefulness.

So when we speak of 'energy' in the sense of something like fuel being consumed or used up, it is really exergy that we mean. Accounting for exergy and useful work allows us to introduce a quality-adjusted measure of natural resource inputs to the economy at their useful stage, i.e. after all transformation and conversion losses, just before becoming energy services in the economy (Santos et al. 2016). Useful exergy accounts for, for example, heat delivered by an electric heater to provide thermal comfort or mechanical work delivered by a car engine, through the driveshaft to the tires, to provide transport. It is a quality-adjusted measure for the energy used productively.

The past 100 years of industrial activity have witnessed dramatic increases in the extraction and supply of exergy (energy and materials) and even faster increases in the delivery of useful work made possible by very significant increases in the exergy (energy) conversion of, for example, prime movers, industrial extraction, 
and processing systems, transport infrastructure, and chemical processes, put together here as the aggregate technical efficiency (Figure 1). Useful work, or exergy * 2nd law efficiency, from natural resource exergy sources (oil, coal, gas, food, fodder, ores) is the missing factor of production, creating a positive feedback cycle of growth ${ }^{2}$ (Figure 2). When used in a similar three-factor production function fit with only two parameters, our model-which is constrained by realistic substitution conditions - is capable of reproducing growth trends for the United States, the United Kingdom, and Japan for the past 100 years (Figure 3).

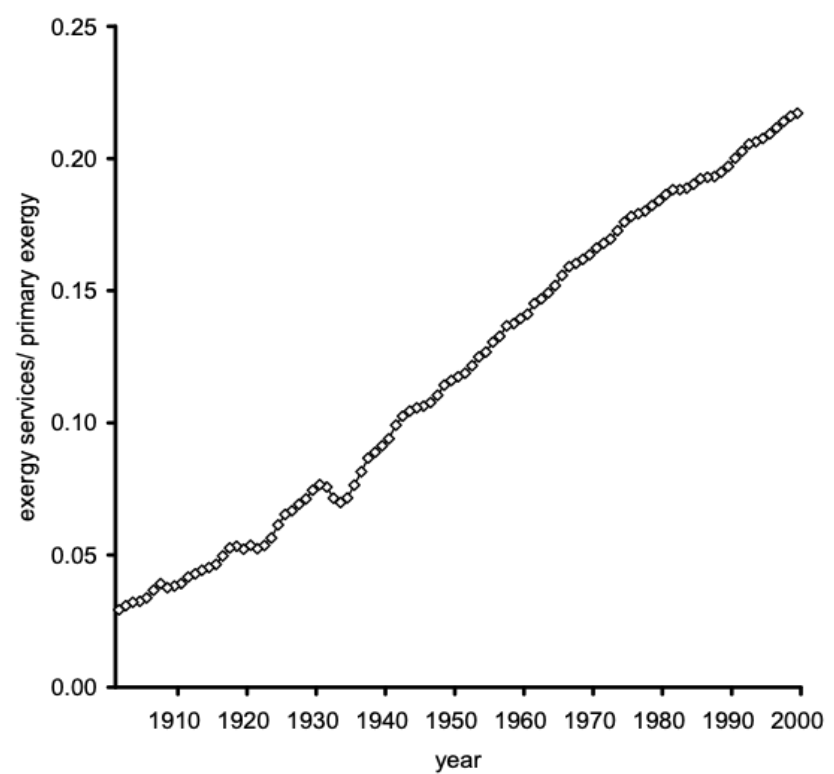

Figure 1 Exergy efficiency improvements, United States of America 1900-2000 (Warr \& Ayres 2006)

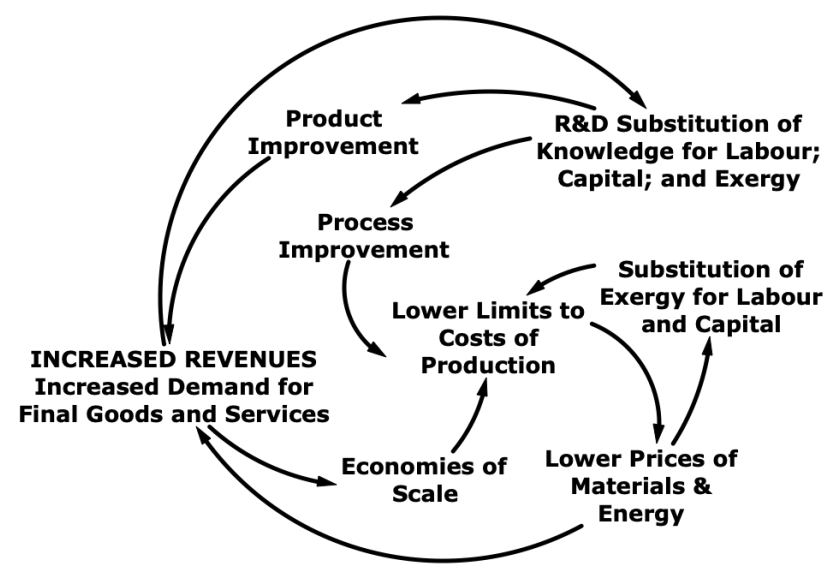

Figure 2 Extended Salter cycle, the engine of growth

\footnotetext{
${ }^{2}$ Note that nature also provides other regulating services that are largely unaccounted for. However, their supply is not increasing, but decreasing.
} 


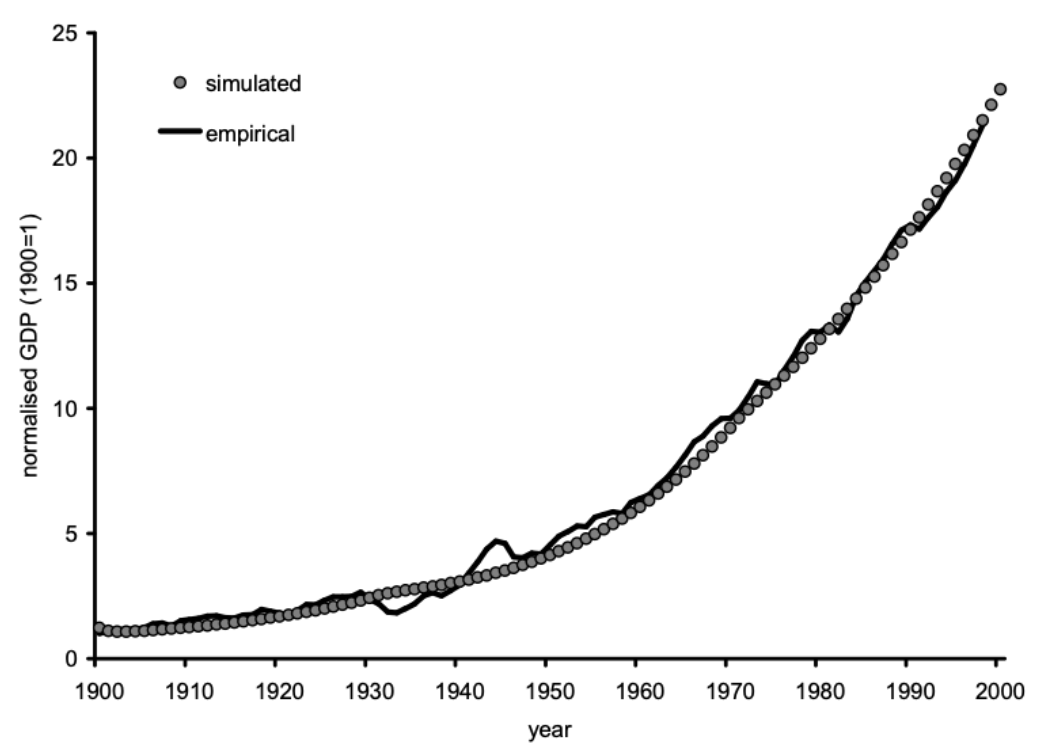

Figure 3 GDP estimate stimulated using REXS model, United States of America 1900-2000 (Warr \& Ayres 2006)

The implications of this work are significant. It shows we are far from an optimal efficiency and that the production possibility curve of the future is constrained by our decisions today, and by existing and future (thermodynamically) possible combinations of capital, energy, and labour (and information). The relationship between factors of production, capital, labour, and energy (natural resources) has changed through industrialisation, as combinations of capital and energy. Energy slaves replace labour in performing physical tasks and will change as artificial intelligence subsequently substitutes information capital and electricity for supervisory and technical roles that are currently performed by people. It explains why disruptions to energy supply, such as the oil shocks of the 1970s and early 1980s, result in larger than expected downturns in economies (Hamilton 2000).

Perhaps, most importantly, it sets out clearly the most significant challenges facing modern societies seeking continuous wealth creation. Let us remind ourselves that ultimately a successful mine closure is largely predicated on the assumption that the mine will generate and put aside adequate finances, and that financial markets are functioning. The principle mechanism of growth over the past 100 years has relied on the continuous decline in energy costs and increases in the efficiency of conversion from exergy to useful work. Put simply, declining costs and increasing performance have stimulated demand and allowed for economies of scale and R\&D in further efficiency improvements in a virtuous growth cycle. We question how much longer this engine can continue without faltering. Society faces two very significant challenges today:

1. Challenge 1: the growth mechanism is the rebound effect resulting from supply and efficiency and increasing information. Increasing efficiencies is increasing demand and total entropy (wastes) production is increasing, meanwhile the resilience of the global ecosystem is declining alarmingly.

2. Challenge 2: we are running out of cheap, high-quality, natural resource exergy and assimilation capacity. Our one-time, non-renewable capital asset account has been drawn on very heavily to the point that we face an existential threat and future generations bear a significant debt burden.

However, the real value of this work is perhaps in bridging gaps between disciplines; in generating connectivity. It provides a space to investigate the potential growth effects of innovations of engineers, miners, and informaticians to dramatically increase the efficiency of systems and by so doing, to reduce wastes $^{3}$. It enables filtering of technological innovations to enable the identification of win-win technologies. Using the language of economics, the production function and much criticised GDP, we have been able to

\footnotetext{
${ }^{3}$ The use of exergy accounting in engineering systems design is well established in mining.
} 
engage with economists in a way that other ecological economists have perhaps not. By revealing that growth is a rebound effect, we have elucidated a dynamic of the complex system, and shown that increased industrial efficiency will-if unchecked or managed-stimulate a growth dynamic that has historically resulted in increased demand, supply, consumption, and ultimately waste generation that outstrips efficiency gains.

This work, focused almost entirely on the technical efficiency of systems, raises important questions for those thinking about the process of mine closure. They range from issues concerning the magnitude of the environmental impact to be managed, a result of inefficiencies in the system, as waste exergy flows do unwanted work on natural systems (pollution), to identification of potential to recover waste exergy flows that may still provide useful work. More generally, it reveals how the non-renewable high grade, high-quality ores and fossil energy from natural resources provided a 'one-time dividend to generate wealth equitably for future generations'. Now facing potential slowdown as we reach limits to growth, and future generations are burdened with debt and a faltering global ecosystem, it is necessary to identify mechanisms that deliver meaningful qualitative diversified and regenerative growth today for post-mining communities that can provide for the necessary costs of regeneration for their future.

\section{Part III: Mine closure, underutilised inventory and incipient resilience}

Even without existential threats and growth challenges illustrated in the previous section, the reality of mine closure is far less clear cut because it too is very much an ongoing and complex process; the success of which is largely determined by the agility of management and resilience of systems throughout the life-of-mine that are subject to failures including:

- Financial reserves are inadequate, non-existent, or diverted.

- Profits move while communities and pollution do not.

- Periods of nationalisation and flip-flop populist policy.

- Pollution that is too hard to handle.

- Mines that never close.

For any variety of reasons, the regeneration of disused mine facilities, particularly in developing countries, does not take place in a timely manner as planned, if at all. Very typically, the process of mine closure has been seen simply as a costly technical problem that the future will solve; one for which there is, or will be, a solution that payment can resolve. But let us be clear, there has been proportionately very little (almost no) real effort to identify those solutions and the sums of money devoted to mine closure in Zambia are trivial. The mine closure plans detailed in environmental impact statements are often very technically vague and financially unequivocal, involving statements of revegetation with native trees and requirements of encapsulating layers of miraculous topsoil (miraculous in that no one quite knows where it will come from or how it will get or stay there).

But this is to overlook the enormous potential to develop important synergies with ongoing mining activities that can assist to reduce costs and to remove price volatilities and supply chain headaches through import substitution, etc., but also to stimulate the creation of a new engine of wealth creation in post-mining communities and expedite the core activity of mining and transform mine closure from the end of everything into the development and continuity of a thriving new sector that could grow with mining and evolve to survive alone. To revisit our discussion, the economics of natural resource consumption and use of the non-renewable asset as a one-off endowment must be used to lay the foundations of a prosperous future beyond mining.

The situation in Zambia provides a useful backdrop to discuss the challenges the mine and these communities face. The Nchanga underground mine in Chingola was opened in 1937 by the Anglo American Corporation. Presently, the Nchanga Open Pit Mines workings, owned and operated by Konkola Copper Mines Plc (KCM), lie in an arc $11 \mathrm{~km}$ long around the west and north of the town, covering nearly $30 \mathrm{~km}^{2}$ (Figure 4). The deepest 
part of the pit is $400 \mathrm{~m}$ lower than the surrounding plateau. The first entry in the Nchanga Consolidated Copper Mines Ltd visitors' book is a Mr H Clark, mining surveyor, and housewife Mrs "Gwendleberry" ${ }^{4}$ Clark. Other visitors over the years have included a plane load of British MPs including Baroness Thatcher (not at the same time), Neil Kinnock, Her Majesty Queen Elizabeth, and perhaps, most interestingly, the South Korean President who wrote to thank "Chingola for providing the copper without which South Korea would never have become developed".

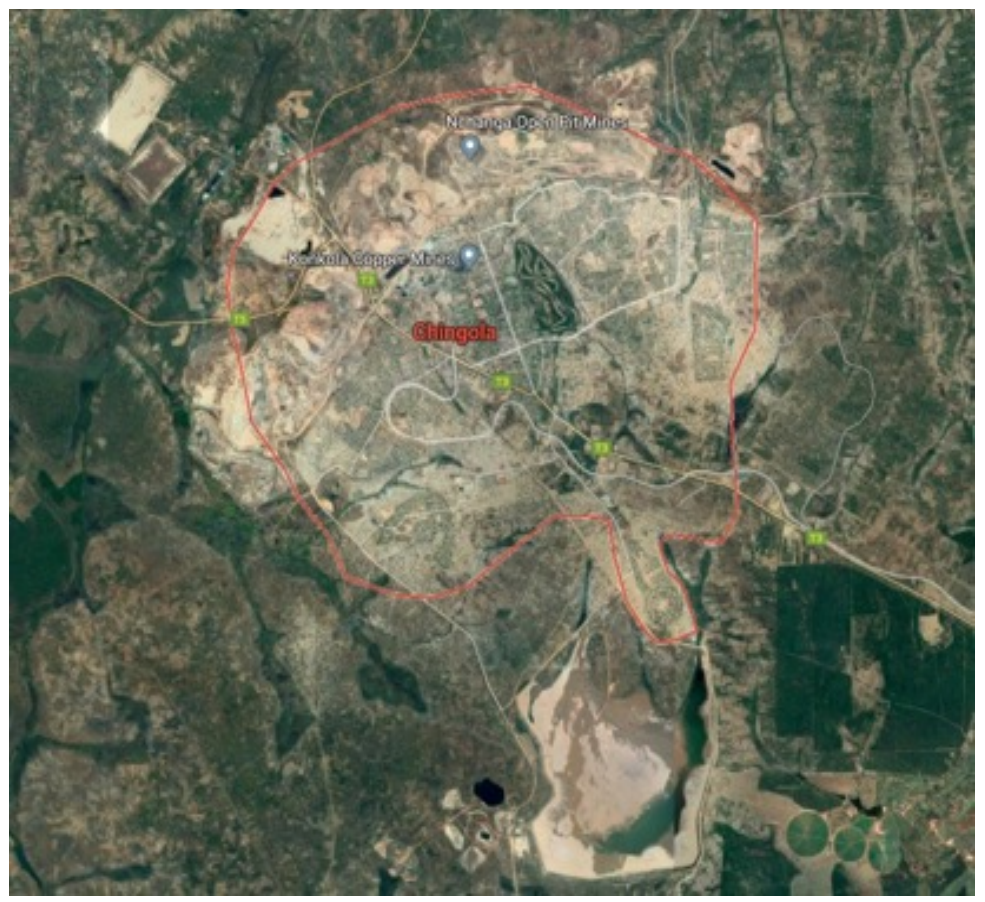

Figure 4 Chingola (Google Earth n.d.) surrounded by mines and disused facilities to the north, south, and west

The long history of the mine reflects the sector within Zambia, being predominantly a privately operated sector until nationalisation of all Zambian mines, which began in 1963 with the Mulungushi and Matero Declarations and government taking a 51\% shareholding in all Roan Selection Trust and Anglo American Corporation mining operations and ended with outright nationalisation by 1972, without reimbursement with production levels at 750,000 $\mathrm{mt}$ (Sikamo et al. 2016). The mines were then largely used to advance a national development agenda suffering undercapitalisation as mines required increasing investment for deeper shafts and more complex ore bodies. Consequently, prices soared, production plummeted $(250,000 \mathrm{mt}$ in 2000), and neither national development agenda nor simple business priorities were achieved. An inevitable and unavoidable reprivatisation process was ready in 1991 and took place six years later, concluding in 2000.

The Vedanta Group purchased Nchanga, Konkola, Nampundwe, and part of Nkana assets in 2004 through their subsidiary KCM. Since reprivatisation over $\$ 2.9$ billion of investment has flowed into KCM operations, much of which was arguably to bring the operations back to some semblance of operability. While often and heavily criticised, the mining sector in Zambia is responsible for $86 \%$ of foreign direct investment, $80 \%$ of the country's export earnings, and $25 \%$ of all tax revenues (Sikamo et al. 2016).

The social and environmental legacy of mining in Chingola inherited by KCM is not so well documented, certainly not as well documented as it has been since they took over operations. Presently, a very high percentage of youth are unemployed and jerabos, as they are known, find what work they can illegally mining tailings and overburden. The mine, while providing for schools, hospitals, employment and market spillovers, is challenged to meet expectations as the only main employer and provider of tax revenues. Dependence on

\footnotetext{
${ }^{4}$ We cannot decipher her name because of the handwriting, but it looks a bit like Gwendleberry!
} 
mining, a single mining company combined with the volatility of commodities markets, impacts suppliers negatively. The economy lacks resilient diversification and this is a problem for $\mathrm{KCM}$, the local community, and Zambia as a nation.

Efforts in Chingola to rehabilitate overburden and tailings facilities have systematically failed. Barren overburden and disused copper tailings facilities surround the town and certain village communities almost entirely. Water and wind erosion from the tailings dumps can be severe (Figure 5). Sedimentation of rivers is severe. Water quality is a major problem. Positive steps to resolve this situation started in 2016; the foundations of which were laid sometime earlier. BetterWorld was founded in 2013 to innovate and implement regenerative social and environmental technologies and business models that worked or showed promise elsewhere to resolve issues at the nexus of food-energy-water, and to investigate their potential in the African context. In 2015, KCM initiated a Go Green Initiative and sought ideas that could put to use underutilised assets such as water and land. Our approach to the design of mine regeneration potential, started with the identification of underutilised inventory, and proceeds to determine whether there exist opportunities to capture or create useful efficiencies and eliminate damaging inefficiencies, with the objective of designing a system that will create an incipient and evolving resilience.

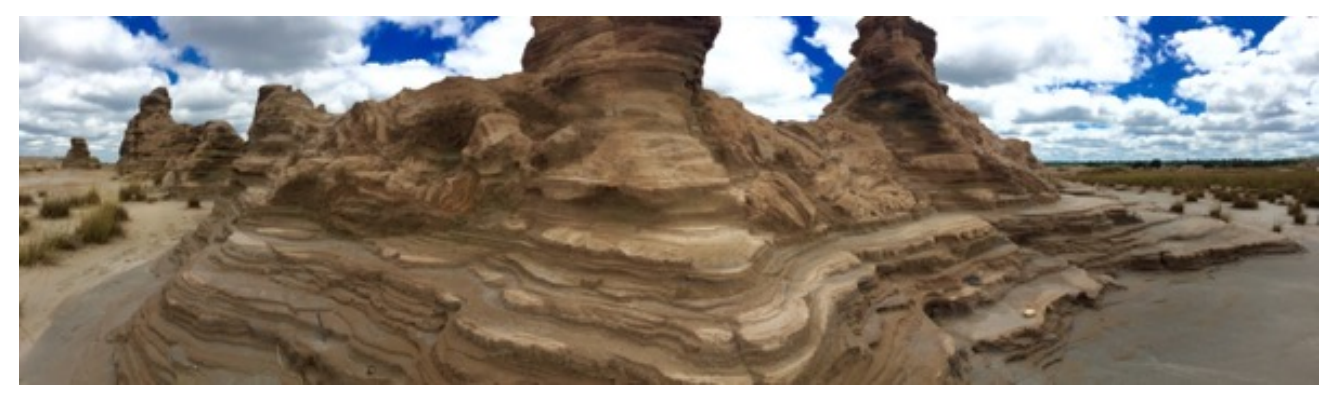

Figure 5 Erosion features at TD2 tailings dam

\subsection{Useful efficiencies and underutilised inventory}

Underutilised inventory is a term we use loosely to define a resource that is not used to its fullest potential in either upstream (capital, land, labour, energy and technology ${ }^{5}$ ) or downstream markets ${ }^{6}$. The large tracts of contaminated land, large communities of unemployed youth, the unused mine waste water pumped into local water courses, and the demand market for fuel unmet by local supplies causing flows of hard earnt FOREX to flow out of the country for imports represented valuable and potentially cheap (even free) resources (inventory) if combined appropriately. Similarly, an unmet demand for effective land regeneration is evidenced by abandoned, unregenerated, disused facilities (Figure 6), expensive regeneration failures and the antagonistic relations between mines and communities. The existence of these low-hanging fruit-that, if effectively harnessed, could give rise to negative cost solutions-is evidence of weak connectivity and restricted flows of information between internal corporate divisions, between the community not directly employed by the mine, innovation communities with new ideas, but also an inappropriate connectivity between mine wastes and the natural environment.

Within an emerging market context where resources are extremely limited, it is essential to consider all dimensions of underutilised inventory to identify potential markets, to minimise unnecessary expenditure and to increase the efficiency of resource use, but perhaps most importantly to determine the presence or absence, form (positive/negative), and strength of the interactions between corporate strategy, and the surrounding complex system than to correct and manage them towards an evolving resilience (DeJong et al. 2015).

\footnotetext{
${ }^{5}$ In economics capital and labour inputs to the production function take into account capacity utilization using measures of equipment downtime or unemployment.

${ }^{6}$ We will use the terms inventory to describe assets, resources, demand, supply interchangeably.
} 


\subsection{Incipient ecological, social, and economic resilience}

The process of generating incipient resilience is predicated on the hypothesis that a lack of resilience has arisen through inexistent, poor, or inappropriate connectivity, and information exchange between the corporate mine entity and the complex dynamic system within which mining and mine facility closure are occurring. Weak, failing, or negative connections span social, economic (business), and environmental dimensions.

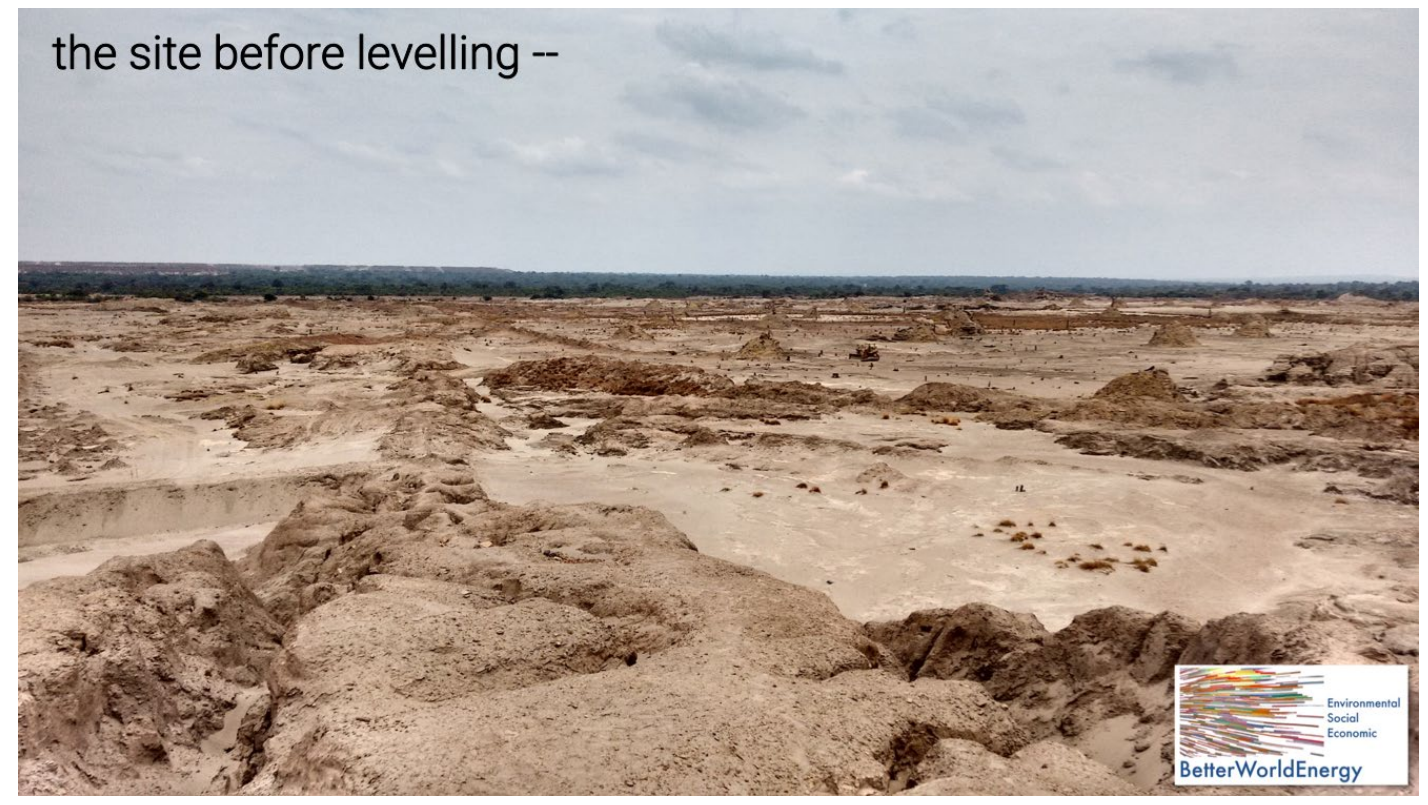

Figure 6 The disused copper tailings facility, TD2 Chingola, before levelling and planting

Technically, land regeneration (tree planting) has failed to meet environmental obligations in Zambia because of:

1. Inappropriate technology transfer which is the result of poor quality interactions with land regeneration experts espousing copy-paste application of standard approaches from wet environments to seasonally dry, brittle environments.

2. Overnight thinking that considers land regeneration to be a one-off plug'n'play activity and therefore does not attempt to provide long-term incentivisation for success. The inappropriate transfer of technology is best illustrated by requirements for encapsulation of facilities with topsoil. This may well represent a fast fix in temperate, wealthy Europe, but in Zambia, the reality is no topsoil was set aside, stockpiled heaps would have eroded, and logistical and environmental costs are unrealistically high ${ }^{7}$ Even if available, application during the dry season would be eroded by wind and in the wet season, by torrential rains. Even if an encapsulation approach was technically and financially possible, as a one-off activity it would remain inappropriate, designed to meet amenity value objectives that simply has no value as it fails to create a robust socio-economic dynamic. A temporary job moving soil, while welcome, does not correspond to a robust and viable economic future. The necessity is to identify a technical solution that generates positive connectivity with both social and economic dimensions, one that can have meaning for the local community (Figure 7).

\footnotetext{
${ }^{7}$ Consider the soil and truck movement needs for a single hectare of topsoil encapsulation to $20 \mathrm{~cm}$ depth, requiring at least 3,200 $\mathrm{mt}$ of soil and approximately 95 truck journeys of a $35 \mathrm{mt}$ truck. A 650 ha site would require over 2 million tons of topsoil and 60,000 truck journeys. Is this 3,200 million tonnes and 2 million tonnes? Or both metric tonnes?
} 


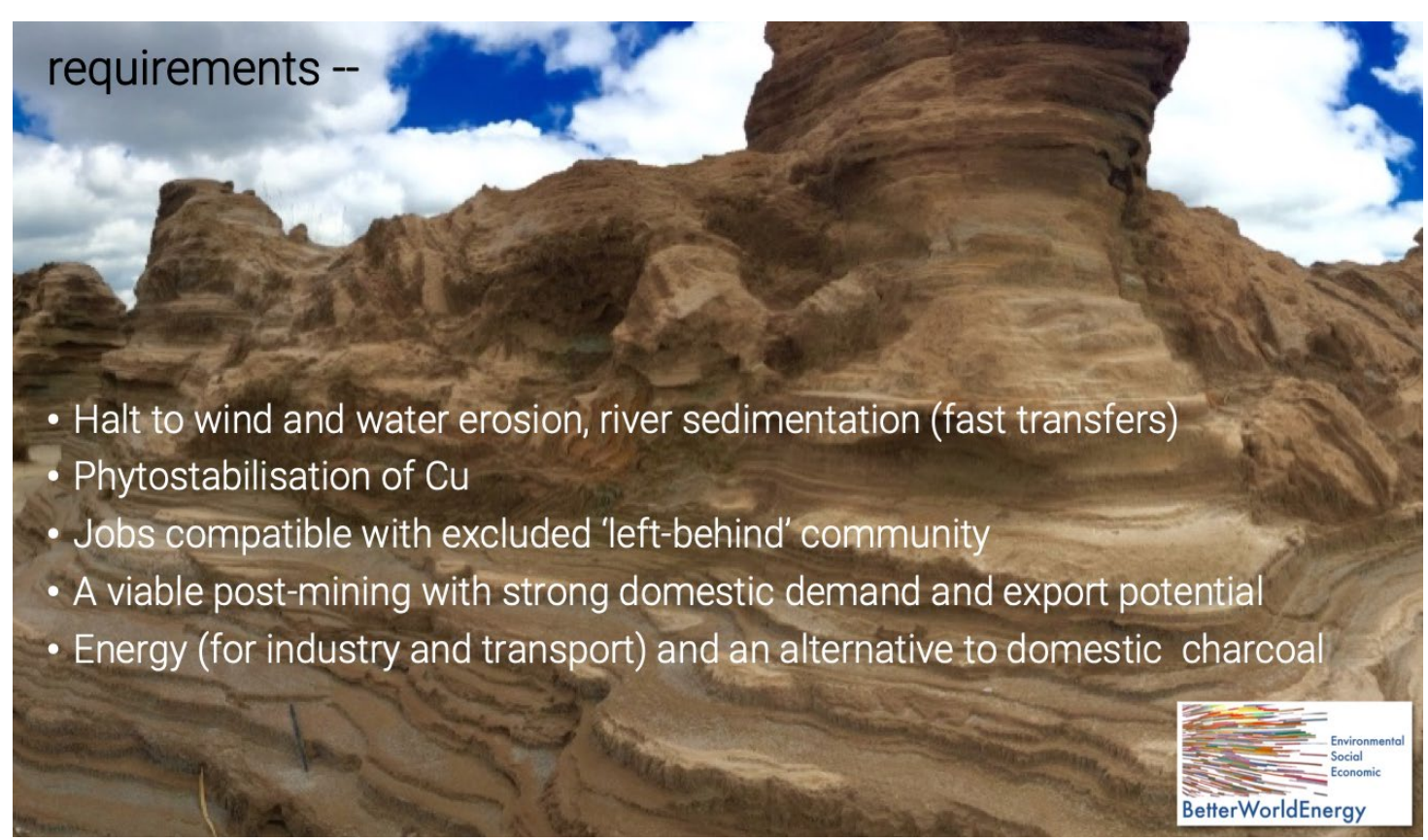

Figure 7 Principle requirements of mine closure activities identified from stakeholders

A technical solution that has been proposed and not tested can also be considered underutilised inventory, as it sits of a shelf gathering dust. There are many such mine restoration ideas out there. Our scoping of possible technical solutions led us to the non-edible, oilseed producing tree elite, Pongamia pinnata (Pongamia) (Figure 8). Good evidence indicated it has an ability to grow in copper contaminated soils and overburden, has modest water requirements ( $>500 \mathrm{~mm} \mathrm{pa}$ ), is capable of tolerating salinity and drought and producing a principle oilseed crop (biodiesel) required by the mine, and byproducts have value to the local community (biogas) and high value low-weight byproducts for export markets (biochemicals of use in agriculture, health, and cosmetics) (Rangan 2013).

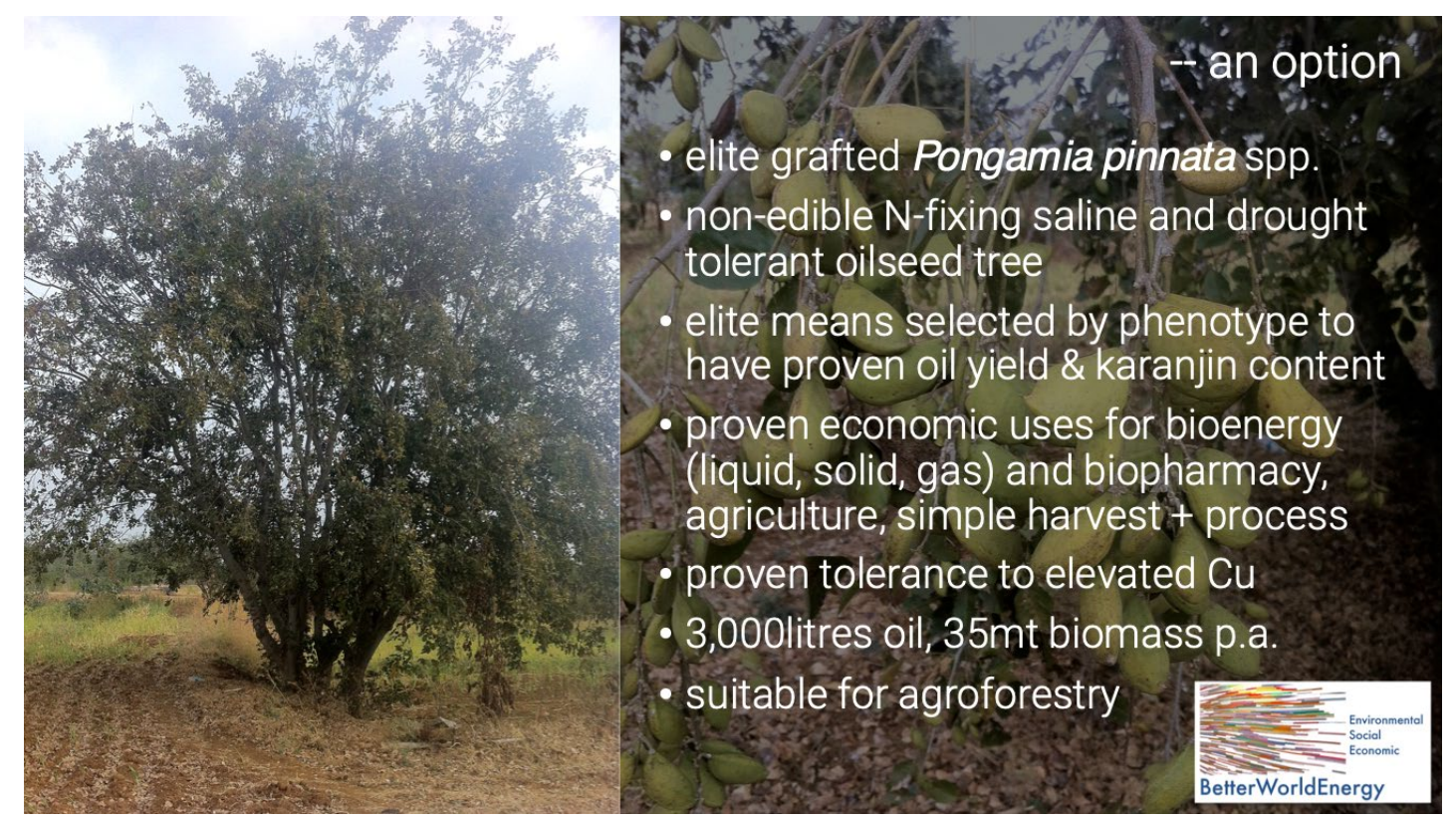

Figure 8 Pongamia pinnata mother tree in a small farmers field India

If Pongamia could survive on the copper tailings with minimal inputs of soil and water, and indications that this $\mathrm{N}$-fixing highly resilient tree could do so were good, then it could offer long-term and life-changing economic opportunities for the unemployed youth of Chingola, as well as the environmental benefits of a 
cleaner environment. It could generate jobs, revenues, and profits that would incentivise successful maintenance of the revegetation activities through the susceptible early years of tree growth, ensuring that both the mines' environmental compliance and local economic diversification obligations are met.

In January 2016, we started work to develop a common understanding across KCM of the potential benefits of the project to each department; a process we call injecting innovation into the corporate matrix. This involved increasing connectivity across the organisation, through joint meetings with finance, commercial, logistics, energy departments, and the executive. We repeatedly engaged to communicate critical information about the project and witnessed a transformation, whereby after eight months, we were encouraged to hear each team talk confidently about the potential benefits of innovation in the direction we proposed versus previously considered alternatives that lacked the holistic vision we encouraged. The common understanding (or positive reinforcing consensus) we created can be considered the foundation stone of an evolving incipient resilience in mine closure. It is based on communication to identify common goals and out of the ordinary approaches.

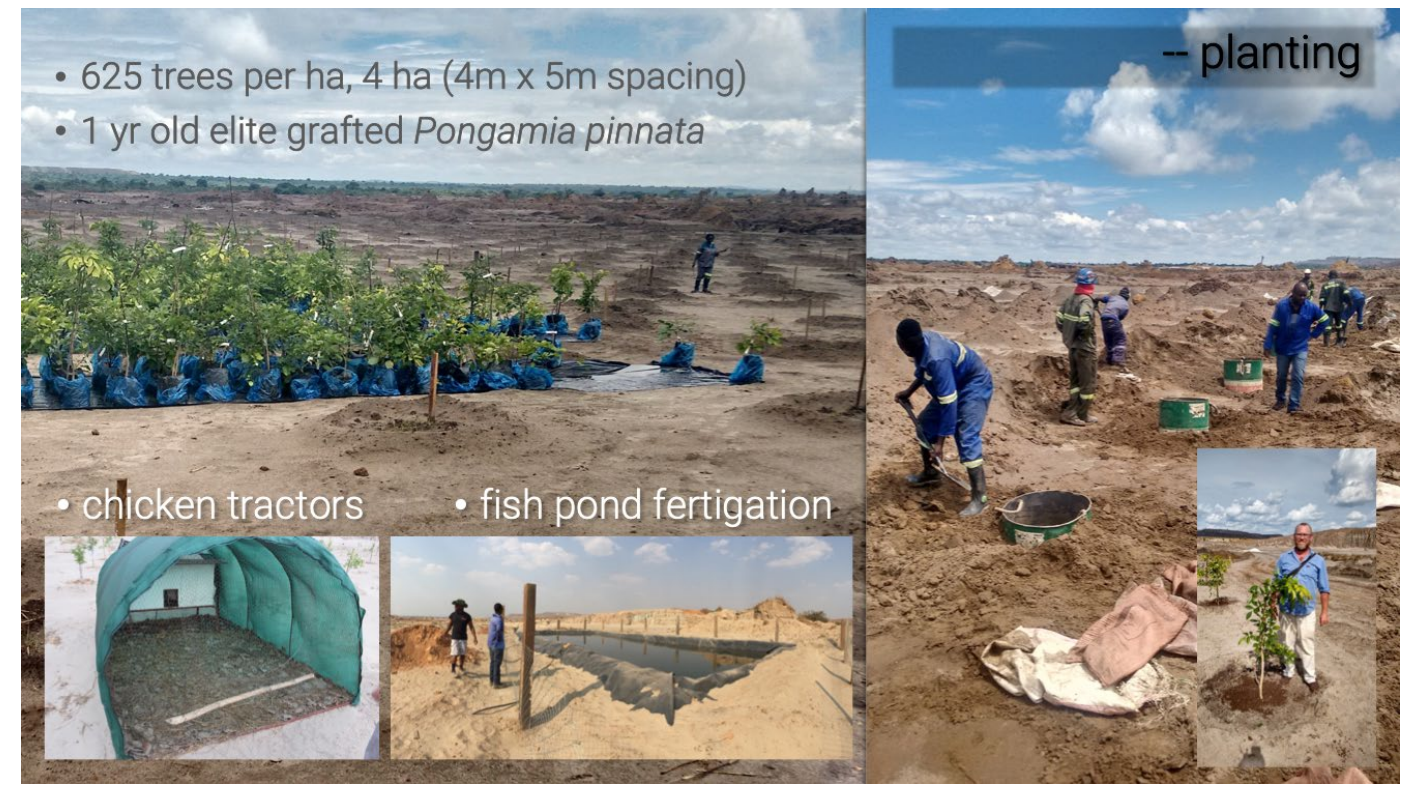

Figure 9 Mens' and ladies' tree planting teams, members of the local community, (inserts, left to right) chicken tractor, fish pond

In December 2016, the first 2,600 elite grafted Pongamia, were planted out on 4 ha of a newly levelled site of tailings dam 2, Chingola, in what is a world first (Figure 9). The tailings dam had been floor washed, leaving a highly erodible and gullied layer of tailings and contaminated soils shaped by wind and water erosion (Figure 5). Copper concentrations of the tailings exceeded 3,500 ppm. Perhaps more troublesome, the sediments are extremely saline $(8,000 \mathrm{ppm} \mathrm{Na}, \mathrm{Ca}, \mathrm{Mg})$ and contain little carbon or nitrogen. By employing lean planting techniques typical of dryland small holder agriculture, each hectare required no more than $20 \mathrm{mt}$ of soil harvested from previously buried termite mounds and $5 \mathrm{mt}$ of organic compost (chicken manure), representing less than $1 \%$ of the topsoil requirements of an encapsulation approach. Clearly, by not encapsulating the tailings, they remain for some time vulnerable to erosion until Pongamia roots bind and fertilise, and natural vegetation colonises the sediments. Throughout the remainder of the wet season, as Chingola is buffeted by very heavy downpours, a dedicated team of four were able to conduct land imprinting and dig check swales to definitively stop all transfers of sediment by water erosion off the site. This approach effectively substitutes for the standard overnight solution (encapsulation) that is natural resource (topsoil) intensive and highly risky, for a slower, keyhole managed process; one that sees financial expenditure go on jobs instead of fuel for trucks to ship costly topsoil (if indeed available). This is an approach that is certainly cheaper, less natural resource intensive (destructive), has a higher chance of meeting immediate goals of reducing erosion, and the advantage of establishing the foundations of a vibrant postmining economy. 
Further context-driven design components were added. To ensure sapling survival, we installed simple and robust hosepipe irrigation systems using mine waste water to hasten tree growth and potentially influence future yields. Applying simple resilience design principles, we introduced a stock of water (a pond) should water supplies be disrupted. Seeing the pond as an underutilised inventory, we sought to stock it with fish. This would have two advantages. Firstly, it would deepen our connectivity and relevance to the local community by providing a source of nutritious food that would also provide a nutrient enriched water for fertigation of the trees. Taking this approach a step further, we introduced layer poultry in moveable chicken tractors to feed the soil and the staff (Figure 8). Both innovations-when envisioned replicated at scale-offer considerable potential to enhance the multi-functionality of the land, speed the regeneration process, and provide jobs and nutrition services that are all beneficial outcomes designed to enhance positive connectivity between ecological, economic, and social outcomes. Various challenges, e.g. severe water erosion, have been controlled through an artisanal land imprinting, involving quite simply a permanent presence of staff to dig trenches and create bunds to control erosion in the first year (Figure 10).

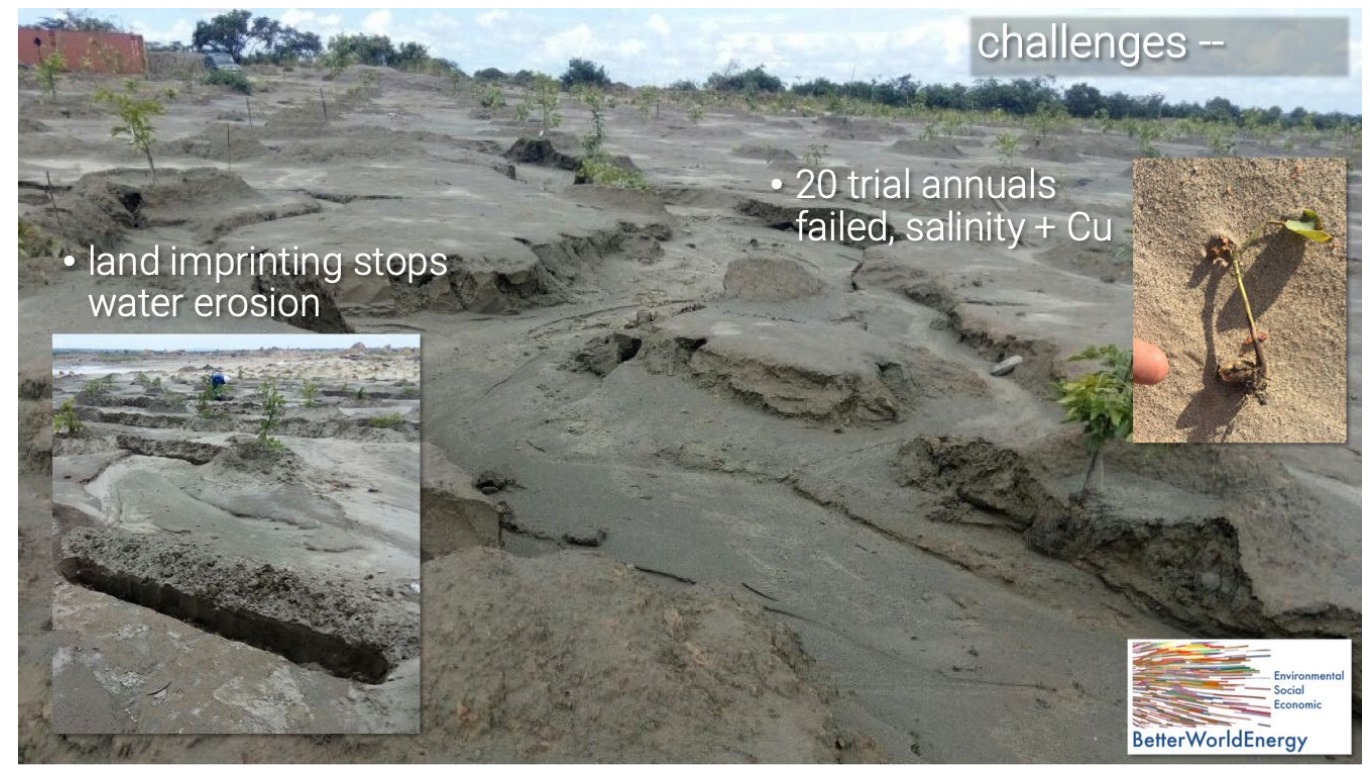

Figure 10 Challenges of erosion and severe salinity

After two years, we report less than $1 \%$ tree mortality, dramatic growth, and normal pod production from the young Pongamia trees. Out of the 30 varieties tested across the site, we have been able to identify clonal varieties that exhibit fast rates of vegetative growth, those which yield early or late, providing for a diverse orchard with reduced yield risk. There are trade-offs. Ultimate yields are likely to be lower than those on prime agricultural soil, but the venture is not a pure one-it is a hybrid-with multiple aligned objectives and revenue streams, the first of which is land regeneration. At this stage, we are able to state with confidence that the trees can survive the worst edaphic conditions and survive through eight months of no rain using $20 \mathrm{~L}$ only, each month, per tree. We have witnessed a total stop to all water erosion and significant lowering of soil surface windspeeds, slowing wind erosion. Further contributing to reduce wind erosion are the spreading islands of regeneration at the base of each tree. Grasses, annuals, and other plant species are colonising the land surface where none had been able in the previous 15 years. Insects, amphibians, small mammals, and birds now venture into the site.

Another trade-off is copper contamination. Pongamia does not (hyper-) accumulate copper. In contrast, it excludes copper at the root. Organic root sloughings then bind with copper in the soil to form highly immoveable organo-cupric complexes, which effectively remain locked at that location in the soil. This approach avoids the would-be significant creation and dispersion of copper contaminated dusts of removal, and additional site contamination of relocating the polluted tailings. But leaves and pods do contain elevated 
levels of $\mathrm{Cu}(100 \mathrm{ppm})$. Fortunately, being non-edible, there is no risk of ingestion ${ }^{8}$ and there are well developed methods for isolation of $\mathrm{Cu}$ from diesel developed by the fossil fuel industry. Similarly, no $\mathrm{Cu}$ remains in biogas and waste slurries of organo-cupric complexes can be returned to the site where they will remain to undergo further pedoturbation and eventual dilution and burial.

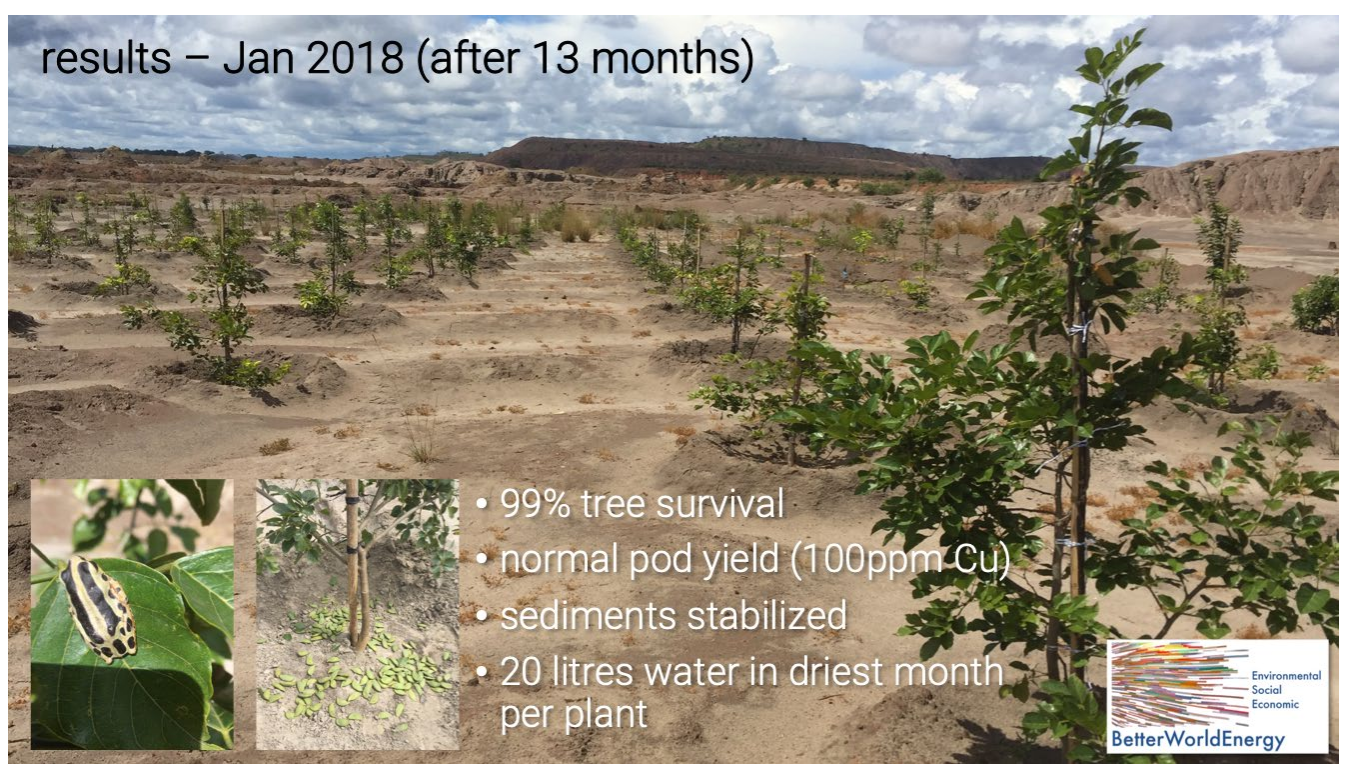

Figure 11 Saplings thriving after two years to produce pod, soils stabilising, biodiversity returning

The benefits of this project are designed to accrue to all stakeholders. For BetterWorld Energy, we have been able to engage with a major corporate and link demand for land regeneration services now with demand for energy supplies with a guaranteed product purchase agreement. We have not had to purchase land, clear forests, or move communities. We have provided an example of a system that will produce biodiesel that does not compete with food production, but rather enhances it, thereby avoiding the rampant criticism of biofuels and the food versus fuel debate. For biofuels producers, the presence of a large underemployed population, collocated with land suitable for planting and a nearly infinite demand for produce is gold dust.

The mine too hopes to benefit. The costs of land regeneration can be recoupled through savings on discounted biodiesel. The provision of some $3 \mathrm{ML}$ per annum from a future 650 ha land regeneration activity will offset some of the $13 \mathrm{ML}$ they consume. Securing low price volatility domestic fuel supplies will reduce operational risk and, importantly, plough back lost money into the local economy, reducing scarce FOREX requirements at a national level. The costs of land regeneration will be lower, simply because they will not need to be repeated or repaired. The long-term incentivisation and mechanisms to ensure tree survival (fertigation fish ponds, chicken tractors, robust simple irrigation), which would not form part of a standard hit-and-run encapsulate-seed regeneration program, are integral to the production model and therefore will be invested in and protected.

Finally, the community will benefit from secure long-term jobs suitable for people (who have not been fortunate to have been educated to a level where they can work for the mine) preparing land and caring for trees, fish, and livestock. Eventually there will be jobs harvesting, processing, and adding value to the Pongamia products, as well as spillover jobs resulting from enhanced energy availability, skills enhancement and so on. These are the very people who should have been benefitting throughout the life-of-mine, but for whatever reason have been excluded, often to the detriment of the mine and society as they seek a living as jerabos or through other informal but often illegal means. Developing this positive social connectivity between the mine and the communities it finds hardest to engage with, is simply another

\footnotetext{
${ }^{8}$ It has been common in Zambia to use mango trees in $\mathrm{Cu}$ polluted areas. These have been found to contain dangerously elevated levels of $\mathrm{Cu}$, and sadly many people harvest and eat these fruit.
} 
mechanism of increasing resilience for the ongoing life-of-mine. As the project advances, extraction and purification of karanjin from the oil will enable diversification into biochemicals production and value addition in agricultural, health, cosmetics and, ultimately, biotechnological research. The future of Chingola will be like its past-leader in innovation, creator of wealth, a hope for the future, an example of how collaborative compromise can create resilience and sustainable wealth while regenerating one of the most damaged locations in the world.

\section{Conclusion}

The first section of this paper introduced the concept of complex systems; managing soil-plant complexity is critical to successful land regeneration and phytostabilisation. The second section asserts that the complexity of mine closure extends throughout the life-of-mine. It also explains how reductionist thinking, including restricted and poor definitions of efficiency, has eroded the resilience of the global ecosystem that will have profound effects on our ability to forecast the future. Uncertainty is the bane of business. A poor definition of corporate efficiency, that fails to include dimensions of the complex system within which mines operate, risks becoming brittle and subject to failure. By designing contextual mechanisms to that fosters positive connectivity between and within the social, environmental, and economic systems, with a strong alignment to core corporate objectives throughout the life-of-mine (cost reductions, reduced volatility, license-tooperate), and which are focused on a time horizon post-closure can facilitate this process. In resource constrained environments/economies, it is useful to focus on systematically identifying the underutilised inventory, defined in the broadest sense, and to consider which ways these can be combined to generate useful connectivity to people, planet, and profits, to overcome constraints and/or mitigate unwanted connectivity in the systems. Fostering useful connectivity across systems creates resilience. In the Pongamia land regeneration project we describe, we sought to create an ecosystem connectivity between plant and soil to stimulate the development of an incipient novel ecosystem that bind soils, improves water infiltration, stabilises copper, and reduces erosion. We sought to create an ecosystem-economy connectivity, as Pongamia provides valuable products for the mining, agricultural, and pharmaceutical industries. We sought to create inclusive societal links to previously excluded communities, arguably those who have suffered most the burden of environmental degradation and failures to re-invest the one-time dividend that natural resource ores can provide to prepare for the future through active efforts to link land regeneration and economic diversification.

\section{References}

Ayres, R 1998, Turning point: An end to the growth paradigm, Earthscan Publications Ltd, London.

Ayres, R \& Kneese, A 1969, 'Production, Consumption and Externalities', American Economic Review, vol. 59, issue 3, pp. $282-297$.

Ayres, R, van den Bergh, J, Lindenberger, D \& Warr, B 2013, 'The underestimated contribution of energy to economic growth', Structural Change and Economic Dynamics, vol. 27, pp. 79-88.

Ayres, R \& Warr, B 2009, The Economic Growth Engine: How Energy and Work Drive Material Prosperity, Edward Elgar Publishing, Cheltenham.

Daly, H 1989, 'Towards an environmental macroeconomics', Ecological Economics, vol. 1, issue 1.

DeJong, J, Tibbett, M \& Fourie, A 2015, 'Geotechnical systems that evolve with ecological processes', Environmental Earth Sciences, vol. 73 , issue 3 .

Faybishenko, B, Hubbard, S, Brodie, E, Nico, P, Molz, F, Hunt, A \& Pachepsky, Y 2016, 'Preface to the Special Issue of on Soil as Complex Systems', Vadose Zone Journal, vol. 15, issue 2.

Fraccascia, L, Giannoccaro, I \& Albino, V 2018, 'Resilience of Complex Systems: State of the Art and Directions for Future Research', Complexity, vol. 2018, pp. 1-44.

Georgescu-Roegen, N 1971, The Entropy Law and the Economic Process, Harvard University Press, Cambridge.

Google n.d., Chingola, retrieved from www.google.com/maps

Jenny, H 1941, Factors of Soil Formation: A System of Quantitative Pedology, McGraw-Hill, New York/London.

Hamilton, J 2000, What is an Oil Shock? National Bureau of Economic Research, Cambridge.

Krasil'nikov, N 2015, Soil Microorganisms and Higher Plants, CreateSpace Independent Publishing Platform, Scotts Valley.

Rangan, L 2013, 'Pongamia - A multipurpose versatile legume', Research Journal of Biotechnology, vol. 8, issue 1, pp. 1-3.

Santos, J, Domingos, T, Sousa, T \& Aubyn, M 2016, Does a small cost share reflect a negligible role for energy in economic production? Testing for aggregate production functions including capital, labor, and useful exergy through a cointegration-based method, University Library of Munich, Munich, https://econpapers.repec.org/paper/pramprapa/70850.htm 
Sikamo, J, Mwanza, A \& Mweemba, C 2016, 'Copper mining in Zambia - history and future'. The Journal of the Southern African Institute of Mining and Metallurgy, vol. 116, no. 6, pp. 491-496.

University of Gröningen n.d., Decision Making in a Complex and Uncertain World, online course, https://www.futurelearn.com/ courses/complexity-and-uncertainty/0/steps/1836

Warr, B \& Ayres, R 2006, 'REXS: A forecasting model for assessing the impact of natural resource consumption and technological change on economic growth', Structural Change and Economic Dynamics, vol. 17, issue 3. 